\title{
Mortality and Its Associated Factors of Bowel Obstruction after Surgical Treatment Among Adult Patients at Debre Markos Comprehensive Specialized Hospital, Northwest Ethiopia 2021 (Retrospective Cross-Sectional Study)
}

Addisu Simachew ( $\sim$ addisusimachew29@gmail.com )

Debre Markos

Dessalegn Haile

Debre Markos

Bekele Tesfaye

Debre Markos

Tiringo Kebede

Debre Markos

Hiowt Nahusenay

Debre Markos

Atirsaw Shimkaw

Debre Markos

Migbaru Endawok

Debre Markos

fasil kefale

Debre Markos

\section{Research Article}

Keywords: Bowel obstruction, Large Bowel, Small Bowel, Treatment Outcomes, Northwest Ethiopia

Posted Date: October 8th, 2021

DOI: https://doi.org/10.21203/rs.3.rs-952644/v1

License: (c) This work is licensed under a Creative Commons Attribution 4.0 International License. Read Full License 


\section{Abstract}

Background: - Bowel obstruction is a mechanical or functional obstruction of bowel that prevents the normal movements of products of digestions. Even if Treatment outcome of bowel obstruction varies from area to area, time to time, and also increasing age is significant factor of treatment outcomes of bowel obstruction. Outcome of bowel obstruction and associated factors on adults have been poorly explored in the previous Ethiopian study particularly in the study area.

Objective: To assess prevalence and its associated factors of mortality after surgical treatment of bowel obstruction among adult patients at Debre Markos comprehensive specialized hospital, Northwest Ethiopia 2021

Methodology: - Institution based Cross sectional study design was used. A total 517 study participates was included by using consecutive sampling techniques from 23/02/2017 to 23/02/2021 at Debre Markos Comprehensive specialized Hospital. Data was collected from patient registration books and medical records available in the hospital by using checklists. Then data were entered to Epi data version 4.1 and exported to SPSS version 25 for analysis. A binary logistic regression model was fitted to identify factors associated with treatment outcome of bowel obstruction. P value less than 0.05 considered as significant in multivariable analysis

Result: Among patients treated for bowel obstruction 70(13.5\%) was died. Old age ( $>=55)((\mathrm{AOR}=3.70 ; 95 \% \mathrm{Cl}[1.02,3.39$, $p=0.046]$, Gangrenous large bowel (AOR 5.58; $95 \% \mathrm{Cl}[2.33,3.36), p=0.0001]$.. prolonged hospital stay $(\mathrm{AOR}=2.42 ; 95 \% \mathrm{Cl}$ $[1.10,5.55, p=0.043])$. late presentation $(A O R=2.84 ; 95 \% \mathrm{Cl}[1.33,6.04])$, comorbidity $(A O R=3.79 ; 95 \% \mathrm{Cl}[(1.75,8.21)$, $p=0.001]), W B C(A O R=3.53 ; 95 \% \mathrm{Cl}[(1.61,7.70), P=0.002])$. Low hemoglobin $(A O R=3.50,95 \% C l[(1,62,7.60), P=0.001])$ was independent predicator of mortality.

Conclusion: Mortality after surgical treatment of bowel obstruction were high and having gangrenous bowel, low hemoglobin level, late presentation, post-operative complications, leukocytosis and comorbidity was independent predicator of unfavorable outcomes. Give special care for patients treated with low hemoglobin, late presentation, having complications and leucocytosis. Create awareness to the public on advantage of early presentation to hospital.

\section{Background}

Bowel obstruction is a mechanical or functional obstruction of bowel that prevents the normal movements of products of digestions[1]. It occurs due to partial or complete interference with the forward flow of small or large intestinal contents. High quality surgical expertise coupled with sound clinical judgment and early surgery when needed will greatly improve survival[2, 3]. Bowel obstruction contributes 12 to $16 \%$ of acute abdomen in emergency[4]. More than 300,000 Patients admit per year and 30,000 deaths annually due to bowel obstruction in USA[5]. Globally 2.1 deaths per 100,000 patients due to bowel obstruction, 3.5 deaths per 100,000 in developed countries and 1.8 deaths in developing country[6]. Patients who have a history of abdominal distention, constipation, prior abdominal surgery, and abnormal bowel sounds may fall into the diagnosis of Bowel obstruction[5]. It remains common cause of acute abdomen that faced surgeons and still have high morbidity and mortality[7, 8].

Bowel obstruction occurs due to different causative agents. The most common causes was mechanical obstructions such as adhesion, hernia, volvulus, malignancy, carcinoma, intussusceptions, and fecal impaction[9, 10]. Among those causes mostly they are vary from state to state and also even differ area to area in the same state. Adhesion is the most common cause of small bowel obstruction in developed country while volvulus and hernia is common in developing country. The remaining less common cause of bowel obstructions is inflammatory bowel disease, mesenteric vascular occlusion, paralytic ileus, stricture, inflammatory tumor, gall stone, foreign body, ileocaecal TB and Koch's abdomen[1114]. 
Since BO mostly treats through surgery in emergency. It causes to complications after post operation, such as surgical site infection, septic shock, and pneumonia postoperatively[19]. Management of bowel obstruction depends largely upon early diagnosis, skillful treatment and managing the pathological effects of the obstruction. Clinical, radiological and operative findings put together can diagnose the obstruction of bowel. The morbidity and mortality rates regarding to bowel obstruction have decrease results from the introduction of new advanced diagnostic tests, fluid and electrolyte correction, more effective antimicrobials and surgical treatment, but the condition still remains a challenging surgical diagnosis. Resection, anastomosis intussusceptions milking, Hartman's, hernia repair, volvulus Derotation and Mekels diverticulectomy were producers to treat bowel obstruction $[3,7,21]$.

Bowel obstruction remains common surgical emergency in the surgical field worldwide. It was the main cause of surgical emergency which cause to high risk of mortality and morbidity in African. Despite advance surgical treatment of bowel obstruction magnitude of unfavorable treatment outcome of BO in Africa was high [23,24]. In Ethiopia bowel obstruction is highly prevalent which cause to surgical emergency secondary to appendicitis and magnitude of mortality of bowel obstruction is high and still has a great problem nationally [25-28].

There are risk factors which contributes to mortality for patients who have BO and treated surgically like age, sex, duration of illness before treatment, length of hospital stay, co morbidity, procedure performed and intra operative finding $[8,26,34,39]$. Even though morbidity and mortality due to bowel obstruction had different factors in the previous studies poorly explored[8]. It is worse in developing countries which lack health care facility, lack health care seeking behavior, these more serious the outcomes related to such like patients who present lately to hospital and cause to mortality. Even if increase medical services and have advance health professionals those who are well familiar with BO pathophysiology, increase infection prevention practice, and access of materials important for early diagnosis of bowel obstruction the problem is continue high. Littlie studies done in our country Ethiopia based on bowel obstruction treatment outcome on adult individuals even if its significantly associated with increased age [35].

Mortality after surgical treatment of bowel obstruction varies from area to area, change from time to time, and also age is significant factor for mortality due to bowel obstruction, it needs recurrent studies for the treatment outcome of bowel obstruction. Moreover variable which was not studied pervious included in this study. There are no publishing studies in the study area of northwest Ethiopia at Debre Markos comprehensive specialized hospital. So the main purpose of these studies is to full fill this gap and recommend accordingly through assessing mortality patients due to bowel obstruction and its associated factor.

\section{Methods And Materials Study design, area and period}

Institutional based cross-sectional study was conducted at DMCSH. Debre Markos Comprehensive Specialized Hospital is found in Northwest Ethiopia, in East Gojjam Zone at Debre Markos Town. Debre Markos is a capital city of East Gojjam Zone, It is $299 \mathrm{~km}$ away from Addis Ababa capital city of Ethiopia and $265 \mathrm{~km}$ from Bihar Dar the capital city of Amhara regional state. It has one Hospital Debre Markos comprehensive specialized hospital that serves for 5 million peoples pear year, it has 41GP,16 specialties and 349 midwifery and nurses ,it provide medical inpatient, surgical inpatient, pediatrics inpatient gynecology and obstetrics inpatient and ophthalmic inpatient treatment service and also pediatrics, adult and emergency outpatient department service. The study was conducted at Debre Markos comprehensive specialize hospital from 23/02/2017 to 23/02/2021.

\section{Sample size determination and sampling procedure}


All patients, who had operative management for bowel obstruction and admitted at Debre Markos comprehensive specialized hospital from September 11 /2018 to March 9 /2019, were included in the study. However, patients with acute appendicitis who had incomplete data record over the variable of interest were excluded from the study. The sample size were determined by census sampling method, in which all acute appendicitis cases operated in Debre Markos referral hospital from September 11/2018 to March 9/2019 were included in the study giving a total sample size of 169 patients.

\section{Data Collection}

Data were collect from patient registration books and medical records available in the hospital through checklists adapted from previous studies[36, 62]. Two professional data collectors and one supervisor were recruited, who were BSc nurses. They were also received training on how to collect data to ensure common understanding of data collection process. First medical record numbers for all the patients with BO in the study period were identify from registration logbooks then their charts were bring out from the card office and those tools including socio-demographic characteristics, clinical manifestation, mortality, causes of obstruction, type of bowel obstruction, length of hospital stay, complications, intra operative procedures, intra operative findings and co morbidity, patients preoperative profile and other relevant clinical variables related to the disease was reviewed.

\section{Statistical analysis}

The collected data was coded and entered using Epi-Data Version 4.2. Then, it was exported to SPSS Version 25 statistical software for further analyses. Descriptive statistics for continuous variables was presented using median and range. Additionally, descriptive summaries for categorical variables were presented using tables, figures, and charts. The presence of outliers and multicollinearity among independent variable was check by Variance inflation factor which was less than 3. Both bivariable and multivariable binary logistic regression models were fitted. Variables with $p$-values $<0.25$ in the Bivariable analysis was entered to the multivariable analysis.

Model goodness of fit was checked in Hosmer-Lemeshow goodness-of-fit at $(p=0.86)$. Variables with $p$-values $<0.05$ in multivariable regression were considered as statistically significant factors of the unfavorable treatment outcome of bowel obstruction. The adjusted odds ratio with its $95 \% \mathrm{Cl}$ was reported in the final binary logistic regression table.

\section{Operational Definition}

Mortality - Death of patients after surgical treatment of bowel obstruction [34].

Length of hospital stay Number of days elapsed while the patient is in the hospital from admission time to discharge or death, if more than 7 day considered as prolonged [34]

Incomplete chart patient's record which had not incorporated variables of interest [59]

\section{Ethics}

The study was carried out after getting approval from Debre Markos University College of health science post graduate research and ethical review committee. Staffs at surgical ward, Card room, and operation room were informed about the aim of the study and verbal consent was taken for the reason to use patient cards and registration books. Confidentiality of the patient's information was assured and the information was recorded in secret. The procedures were in compliance with Helsinki Declaration. 


\section{Results}

\section{Socio-demographic characteristics}

In this study 517 respondents were included and response rate of 100\%, among those $413(79.9 \%)$ and $104(20.1 \%)$ were males and female. Age group from 15-24 was 17.4\%, $25-34$ accounts $18 \%, 35-44$ accounts $17 \%$, and $25 \%$ of the respondents were in the age group (>=55) the median age of the participants was $45 \pm 26$ (IQR) (Table 1).

Table 1

Socio-demographic characteristics of the study Prevalence and its associated factors of mortality after surgical treatment of bowel obstruction among adult patients at Debre Markos comprehensive specialized hospital, Northwest Ethiopia $2021(n=517)$

\begin{tabular}{|llll|}
\hline Variable & Category & Frequency & Percent (\%) \\
\hline Sex & Male & 413 & $79.9 \%$ \\
\cline { 2 - 4 } & Female & 104 & $20.1 \%$ \\
\hline \multirow{2}{*}{ Age } & $15-24$ & 90 & $17.4 \%$ \\
& $25-34$ & 93 & $18 \%$ \\
& $35-44$ & 88 & $17 \%$ \\
& $45-54$ & 117 & $22.6 \%$ \\
\cline { 2 - 4 } & $=>55$ & 129 & $25 \%$ \\
Residency & Rural & 457 & $88.4 \%$ \\
\cline { 2 - 4 } & Urban & 60 & $11.6 \%$ \\
\hline
\end{tabular}

\section{Sign And Symptoms Of Bowel Obstruction}

All patients $517(100 \%)$ complain abdominal pain followed by abdominal distention and vomiting (figure1)

\section{Cause BO and types of procedure performed}

As shown in this study volvulus was the main cause of bowel obstruction, $37.2 \%$ of SBO was cause due to volvulus and LBO caused by sigmoid volvulus was $36 \%$ followed by adhesion, hernia and intussusceptions.

As findings of this study De-rotation of bowel was the main procedure to treat bowel obstruction surgically which accounts $39.8 \%$ followed by anastomosis and resection of bowel (39.3). Patients treat through anastomosis and resection accounts $72.9 \%$ from the total of 70 died patients (figuer3).

\section{Mortality, postoperative diagnosis and complication of BO}

The findings of these studies shows $13.5 \%$ of the respondent was died after surgical treatment of bowel obstruction and $86.5 \%$ was discharge with improvement. SBO accounts $60.5 \%$ and LBO $39.5 \%$ of bowel obstruction. There were $0.6 \%$ preoperative and post-operative diagnosis discrepancies. 3 patients in the preoperative diagnosis was SBO but postoperatively diagnosed as LBO and the discharge alive with improvement. From total participants $24.8 \%$ patients develop post-operative complications like SSI, wound dehiscence, pneumonia and sepsis (Table2). 
Table 2

postoperative diagnosis and mortality status of patients treated surgically for bowel obstruction among adult patients admitted at DMCSH North West Ethiopia 2021(n=517)

\begin{tabular}{|c|c|c|c|c|c|c|}
\hline Variables & Category & & Frequency & $\begin{array}{l}\text { Percent } \\
\text { (\%) }\end{array}$ & $\begin{array}{l}\text { Discharge with } \\
\text { improvement }\end{array}$ & Died \\
\hline \multirow[t]{3}{*}{ postoperative diagnosis } & SBO & & 313 & $60.5 \%$ & 288 & 25 \\
\hline & LBO & & 204 & $39.5 \%$ & 159 & 45 \\
\hline & Total & & & $100 \%$ & 447 & 70 \\
\hline \multirow{12}{*}{$\begin{array}{l}\text { Postoperative } \\
\text { complication }\end{array}$} & SSI & Yes & 56 & $12.8 \%$ & 25 & 31 \\
\hline & & No & 441 & $87.2 \%$ & 402 & 39 \\
\hline & Total & & 517 & $100 \%$ & 427 & 70 \\
\hline & Wound dehiscence & Yes & 13 & $10.3 \%$ & 5 & 8 \\
\hline & & No & 504 & $89.7 \%$ & 442 & 62 \\
\hline & Total & & 517 & $100 \%$ & 447 & 70 \\
\hline & Pneumonia & Yes & 34 & $10.4 \%$ & 24 & 10 \\
\hline & & No & 483 & $89.6 \%$ & 423 & 60 \\
\hline & Total & & 517 & $100 \%$ & 447 & 70 \\
\hline & Sepsis & Yes & 25 & $6.8 \%$ & 11 & 14 \\
\hline & & No & 492 & $93.2 \%$ & 426 & 66 \\
\hline & Total & & 517 & $100 \%$ & 447 & 70 \\
\hline \multirow{2}{*}{$\begin{array}{l}\text { Post-operative diagnosis } \\
\text { discrepancy }\end{array}$} & Yes & & 3 & $0.6 \%$ & 3 & 0 \\
\hline & No & & 514 & $99.4 \%$ & 444 & 70 \\
\hline \multirow[t]{2}{*}{ Mortality } & Yes & & 70 & $13.5 \%$ & & \\
\hline & No & & 447 & $86.5 \%$ & & \\
\hline
\end{tabular}

\section{Factors associated mortality after surgical treatment of BO}

Mortality of patients after surgical treatment of bowel obstruction was affected by various risk factors. In bi-variable logistic regression age, types of $\mathrm{BO}$, pre \& postoperative complications, intraoperative findings, types of procedures performed, WBC, Hemoglobin, length of hospital stay, duration of illness before treatment, comorbidity, temperature, heart rate and hematocrit were their $p$ value less than 0.25 recruit for multivariable logistic regression. In the multivariable analysis $p$ value less than 0.05 considered as significantly associated with bowel obstruction treatment outcomes, such as intra operative findings of gangrenous small and large bowels, length of hospital stay, duration of illness before treatment, comorbidity, Hemoglobin, WBC, post \& pre-operative complications and age was independent predicator of mortality for adult patients treated surgically.

The odds of gangrenous large bowel obstructions to cause mortality after treated bowel obstruction surgically was 5.5 times higher than viable large bowel (AOR 5.58; 95\% CI [2.33, 3.36), $p=0.0001]$. The odds old age $(>=55)$ to cause mortality after treatment of bowel obstruction surgically was 3.7 times higher than compared with age groups (15-24) 
years old ((AOR=3.70; 95\% Cl [1.02,3.39, $\mathrm{p}=0.046]$. The odds of prolonged period of hospital stay to develop of mortality after bowel obstruction treated surgically was nearly 2.4 times higher than compared with those discharge early (AOR= $2.42 ; 95 \% \mathrm{Cl}[1.10,5.55, \mathrm{p}=0.043])$. The odds of late presentation to hospital to develop mortality after treated bowel obstruction surgically was 2.8 folds higher than patients present early (AOR=2.84; 95\% $\mathrm{Cl}[1.33,6.04])$.

The odds of comorbidity to develop mortality after treatment of bowel obstruction surgically were 3.8 times more likely than those without comorbidity $(\mathrm{AOR}=3.79 ; 95 \% \mathrm{Cl}[(1.75,8.21), \mathrm{p}=0.001])$. WBC was significantly associated with treatment outcomes of bowel obstruction. The odds of leukocytosis to develop mortality of after patients treated bowel obstruction surgically was 3.5 times higher compared to patients with normal WBC number ( $\mathrm{AOR}=3.53 ; 95 \% \mathrm{Cl}[(1.61$, 7.70), $P=0.002])$. The odds of low hemoglobin to cause mortality after bowel obstruction treated surgically was 3.5 more than patients with normal hemoglobin level (AOR=3.50, 95\% $\mathrm{Cl}[(1,62,7.60), \mathrm{P}=0.001])$. 
Table 3

Bi-variable and multivariable logistic regression for predicating of mortality of patients treated bowel obstruction surgically at Debre Markos Comprehensive specialized hospital North West Ethiopia from February 23/2017- February $23 / 2021(n=517)$

\begin{tabular}{|c|c|c|c|c|c|c|c|}
\hline \multicolumn{2}{|c|}{ Predicator Variables } & \multicolumn{2}{|l|}{ Outcome } & \multirow[t]{2}{*}{ COR at $(95 \% \mathrm{Cl})$} & \multirow{2}{*}{$\begin{array}{l}\mathrm{P} \\
\text { value }\end{array}$} & \multirow{2}{*}{$\begin{array}{l}\text { AOR at } \\
95 \% \mathrm{Cl})\end{array}$} & \multirow[t]{2}{*}{$P$ value } \\
\hline & & $\begin{array}{l}\text { Un- } \\
\text { favorable }\end{array}$ & $\begin{array}{l}\text { Favor } \\
\text { able }\end{array}$ & & & & \\
\hline \multirow[t]{5}{*}{ Age } & $>=55$ & 39 & 90 & $9.3(3.20,7.17)$ & 0.0001 & $\begin{array}{l}3.70(1.02, \\
3.39)\end{array}$ & $0.046^{*}$ \\
\hline & $45-55$ & 15 & 102 & $3.10(1.01,9.88)$ & 0.48 & $1.1(0.28,4.41)$ & 0.88 \\
\hline & $35-44$ & 7 & 81 & $1.85(0.52,6.58)$ & 0.33 & $\begin{array}{l}0.72(0.15 \\
3.46)\end{array}$ & 0.68 \\
\hline & $25-34$ & 5 & 88 & $1.22(0.32,4.70)$ & 0.77 & $\begin{array}{l}0.35(0.69 \\
1.80)\end{array}$ & 0.21 \\
\hline & $15-24$ & 4 & 86 & 1 & & 1 & \\
\hline \multirow[t]{2}{*}{$\begin{array}{l}\text { Preoperative } \\
\text { complication }\end{array}$} & Yes & 40 & 75 & $\begin{array}{l}6.61(3.87- \\
11.28)\end{array}$ & 0.0001 & $4.44(2.06,9.60)$ & $0.0001^{\star}$ \\
\hline & No & 30 & 372 & 1 & & 1 & \\
\hline \multirow[t]{2}{*}{$\begin{array}{l}\text { Preparative } \\
\text { diagnosis }\end{array}$} & LBO & 42 & 154 & $2.85(1.70-4.78)$ & 0.0001 & $\begin{array}{l}1.18(0.47 \\
1.95)\end{array}$ & 0.71 \\
\hline & SBO & 28 & 293 & 1 & & 1 & \\
\hline \multirow[t]{3}{*}{$\begin{array}{l}\text { Intraoperative } \\
\text { finding }\end{array}$} & LBV(gangrenous) & 39 & 101 & $\begin{array}{l}8.22(4.22 \\
16.04)\end{array}$ & 0.0001 & $\begin{array}{l}5.58(2.33 \\
3.36)\end{array}$ & $0.0001^{\star}$ \\
\hline & SBV(gangrenous) & 18 & 69 & $5.55(2.60,11.89)$ & 0.0001 & $3.1(1.17,8.17)$ & $0.022^{*}$ \\
\hline & Viable bowel & 13 & 277 & 1 & & 1 & \\
\hline \multirow[t]{2}{*}{$\begin{array}{l}\text { Procedure } \\
\text { performed }\end{array}$} & Anastomosis / R & 49 & 146 & 4.81(2.78-8.32) & 0.0001 & $\begin{array}{l}1.26(0.55 \\
2.80)\end{array}$ & 0.57 \\
\hline & $\begin{array}{l}\text { Non anastomosis } \\
\text { procedure }\end{array}$ & 21 & 301 & 1 & & 1 & \\
\hline \multirow[t]{2}{*}{$\begin{array}{l}\text { Postop } \\
\text { complication }\end{array}$} & Yes & 45 & 83 & $\begin{array}{l}7.89(4.58- \\
13.59)\end{array}$ & 0.0001 & $2.38(1.07,5.30)$ & $0.032^{*}$ \\
\hline & No & 25 & 364 & 1 & & & \\
\hline \multirow[t]{2}{*}{ Comorbidity } & Yes & 37 & 72 & $5.84(3.42-9.99)$ & 0.0001 & $\begin{array}{l}3.79(1.75 \\
8.21)\end{array}$ & $0.001 *$ \\
\hline & No & 33 & 375 & 1 & & 1 & \\
\hline \multirow{2}{*}{$\begin{array}{l}\text { Duration of } \\
\text { illness before } \\
\text { Rx }\end{array}$} & $>24$ & 39 & 157 & $2.32(1.39-3.87)$ & 0.0001 & $2.84(1.33,6.04)$ & $0.007 *$ \\
\hline & $<=24$ & 31 & 290 & 1 & & 1 & \\
\hline \multirow{2}{*}{$\begin{array}{l}\text { Length of } \\
\text { hospital stay }\end{array}$} & $>7$ & 32 & 78 & $5.30(3.12-9.00)$ & 0.0001 & $2.42(1.10,5.35)$ & $0.029 *$ \\
\hline & $<=7$ & 33 & 369 & 1 & & 1 & \\
\hline Heart rate & Tachycardia & 37 & 146 & $2.51(1.48-4.25)$ & 0.001 & $1.22(0.54,2.74)$ & 0.62 \\
\hline
\end{tabular}




\begin{tabular}{|c|c|c|c|c|c|c|c|}
\hline & Bradycardia & 4 & 13 & $3.05(0.93-9.98)$ & 0.001 & $\begin{array}{l}1.71(0.28 \\
10.44)\end{array}$ & 0.56 \\
\hline & Normal & 29 & 288 & 1 & & 1 & \\
\hline \multirow[t]{3}{*}{ Temperature } & Fever & 20 & 43 & $3.84(2.08-7.07)$ & 0.000 & $1.86(0.65,5.31)$ & 0.24 \\
\hline & Hypothermia & 3 & 16 & $1.54(0.43,5.5)$ & 0.500 & $0.45(0.75,2.73)$ & 0.38 \\
\hline & Normal & 47 & 388 & 1 & & 1 & \\
\hline \multirow[t]{2}{*}{ Hemoglobin } & Low & 32 & 64 & $5.03(5.93,9.64)$ & 0.000 & $3.5(1.62,7.6)$ & $0.001 *$ \\
\hline & Normal & 38 & 383 & 1 & 1 & & \\
\hline \multirow[t]{2}{*}{ Hematocrit } & Low & 29 & 80 & $3.24(1.90-5.53$ & 0.000 & $\begin{array}{l}1.55(0.50 \\
4.70)\end{array}$ & 0.44 \\
\hline & Normal & 41 & 367 & 1 & & 1 & \\
\hline \multirow[t]{3}{*}{ WBC } & Leukocytosis & 35 & 138 & $2.38(2.08-7.07)$ & 0.001 & $\begin{array}{l}3.53(1.61, \\
7.70)\end{array}$ & $0.002 *$ \\
\hline & Leucopenia & 6 & 36 & $1.56(0.61-4.03)$ & 0.35 & $0.73(0.22,2.44)$ & 0.61 \\
\hline & Normal & 29 & 273 & 1 & & 1 & \\
\hline
\end{tabular}

\section{Discussion}

As report shown in this study mortality of patients after treated surgically for bowel obstruction were (70) $13.5 \%$ (95\% Cl; $(10.6 \%, 16.6 \%)$ which were died in the hospital and (447)86.5\% was discharge with improvement. Which is consistent with studies at Southern India 14\%[7], turkey 12.8\%[8], Lagos university teaching hospital 14.3\%[24] and delta state university teaching hospital Nigeria $15.3 \%[45]$ and Ethiopia $11 \%, 12.1 \% \& 13 \%[9,35,36]$.

It is high compared to studies in Chiro general hospital 3.9\%[26]. The difference might be due to socio-demographic characteristics of the population only $11 \%$ of the population study $>=55$ years in Chiro general hospital where as in this study $27.1 \%$ of patients age was $>=55$ years old and types of procedure done in this study anastomosis and resection of bowel was significantly associated with death but not in Chiro general hospital. It is low compared with studies in in Barcelona Spain 18.8\%[44] and Malawi 18.6\%[46]. The possible reason of the difference might be due to sociodemographic characteristics of the participants, the mean age of patients in this study was 43.8 but 67.47 at Spain which was significantly associated with mortality and in this study patients treated in referral hospital but in Malawi patients treated at district hospital which has low infrastructures.

There are various factors responsible for mortality after patients treated surgically for bowel obstruction. The sociodemographic characteristic that was significantly associated with treatment outcomes of BO was age. Old age( >=55 )was significantly affect bowel obstruction treatment outcome nearly 3.7 times more likely unfavorable outcome than those with age group (15-24) at p value 0.046. This is in line with similar studies in turkey[8], India[39], Bangladesh[54], and Chiro referral hospital[26] respectively. The possible reason may be due to advance age is risk for postoperative complication and death[63]

In this study intraoperative finding was significantly associated with treatment outcomes of bowel obstruction. Gangrenous bowel significantly associated with unfavorable outcomes of bowel obstruction. This is in line with studies in Kenya [23], Nigeria[19], Chiro[26] and Adama[59]. but it is contradict studies in Gondar University[47]. The difference 
might be due to in this study $37.9 \%$ of Patients present to hospital late which accounts $55.7 \%(39)$ death from the total 70 deaths. Post-operative complication was highly significant association with treatment outcomes of bowel obstruction. Patients who developed postoperative complication cause to unfavorable outcomes than those not yet develop postoperative complications which are supported by studies at Atthat Chatolic Hospital[34]. The possible reason for postoperative complication might be due to abdominal surgery by its nature cause to complications like surgical site infection, bowel obstruction surgery is mostly done as emergency and also old ages is risk factor for postoperative complications and death[63,64]. Preoperative complication also leads to unfavorable outcomes of bowel obstruction which is consistent with studies at Jimma[36].

The finding of this study showed that late presentation of patients to hospital was significantly associated with poor treatment outcomes of bowel obstruction. Patients present after 24 hours of disease onset more likely had poor outcome than those who present within 24 hours of disease onset. This in line with studies in D.Y.Patil Hospital, Navi Mumbai[3], turkey[8], India[39],Tanzania[51], Lady Curzon Hospital India [65], and Nigeria[19]. These cause to bowel damage and post-operative complications. The possible reason may be low health seeking behavior and transport problem, since most of the individuals comes from rural area. To improve this creates awareness for the public for advantages of early presentation to hospital and surgical treatment.

Length of hospital stays also highly significant association with bowel obstruction treatment outcome. Patients admitted more than 7 days in the hospital cause to poor outcomes which is supported by studies conducted in Kenya[23] and Adama[59]. This might be due to Long period of hospital stay lead to hospital acquired infection. In this study $24.8 \%$ of the respondents develop post operation complications and $21.1 \%$ had comorbidity both of this cause to prolonged hospital stay and associated with mortality after and during bowel obstruction treated surgically[66, 67]. WBC significantly associated with treatment outcomes of bowel obstruction. Patients those who had leukocytosis significantly associated with poor treatment outcomes of bowel obstruction. This is in line with studies in turkey [55]. Comorbidity significantly affects treatment outcomes of bowel obstruction negatively which is supported by studies in Turkey[8]. The possible reason might be due to mostly comorbidity occur in aged groups [68] and in this study $25 \%$ of the respondent was ( $>=55$ ) years old and those were significantly associated with mortality. Aggressive evaluation of comorbidities as much as possible is important to improve postoperative outcomes[69]. Hemoglobin was significantly associated with treatment outcomes of bowel obstruction. Having low hemoglobin was significantly associated with poor treatment outcomes of bowel obstruction.

\section{Conclusion}

Based on the finding of these study poor treatment outcomes of bowel obstruction that was treated surgically at DMCSH was high. Having intraoperative findings of gangrenous bowel, long period of hospital stay, old age, pre-operative complications, postoperative complications, low hemoglobin, leukocytosis and late presentation to hospital were found independent predicator of unfavorable outcomes. Appropriate preoperative, intra and post-operative management, high quality surgical intervention and sound clinical judgment can be reduce risk of death. Create awareness to the population for clinical presentation, advantage of early presentation to hospital this important to early detection of disease and providing early surgical interventions. Providing special care should be consider for those patients in old aged group to reduce mortality.

\section{Limitation of the study}

It was impossible to measure some essential parameters, which may significantly contribute for outcomes of BO like Educational status of the patients, Occupational status, and House hold income per month since secondary data was 
utilize in this study. The results of the study may not show the actual picture of the problem in the community since this study was institutional based study.

\section{Declarations}

\section{Acknowledgments}

The authors would like to thank Debre Markos comprehensive specialized Hospital administration, health workers and data collectors.

\section{Author Contributions}

All authors contributed to data analysis, drafting or revising the article, have agreed on the journal to which the article will be submitted, gave final approval to the version to be published, and agree to be accountable for all aspects of the work.

\section{Disclosure}

The authors report no conflicts of interest for this work.

\section{Competing interests}

The authors declare that they have no competing interests.

Consent to publish is not applicable

\section{Availability of data and materials}

All the data include in the manuscript can be accessed from the Corresponding author with an addisisusismachew29@gmail.com

\section{References}

1. Fitzgerald, J. and F. Edward, Small bowel obstruction. Emergency Surgery, 2010: p. 74-79.

2. Prasad, M., A. Pathak, and R. Gupta, Incidence of acute intestinal obstruction in adults in Eastern India. Int J Med Health Res, 2017. 3: p. 25-9.

3. Deolekar, S.R., et al., A study of surgical management and its outcome in adult patients with intestinal obstruction. International Surgery Journal, 2019. 6(12): p. 4370-4377.

4. Zinner, M.J., S.W. Ashley, and O.J. Hines, Maingot's abdominal operations. 2019: McGraw-Hill Education.

5. Gore, R.M., et al., Bowel obstruction. Radiologic Clinics, 2015. 53(6): p. 1225-1240.

6. Stewart, B., et al., Global disease burden of conditions requiring emergency surgery. Journal of British Surgery, 2014. 101(1): p. e9-e22.

7. Aquinas, B., A study on the surgical management of acute intestinal obstruction in adults. 2014, Thanjavur Medical College, Thanjavur.

8. Kapan, M., et al., Mechanical bowel obstruction and related risk factors on morbidity and mortality. Journal of Current surgery, 2012. 2(2): p. 55-61.

9. Olani, A., et al., Small bowel obstruction: clinical presentation and surgical outcomes at Jimma University Medical Centre in southwest Ethiopia. Gastrointestinal Nursing, 2020. 18(8): p. 22-28. 
10. Tiwari, S.J., R. Mulmule, and V.N. Bijwe, A clinical study of acute intestinal obstruction in adults-based on etiology, severity indicators and surgical outcome. Int J Res Med Sci, 2017. 5(8): p. 3688-96.

11. Tiwari, S.J., R. Mulmule, and V.N. Bijwe, A clinical study of acute intestinal obstruction in adults-based on etiology, severity indicators and surgical outcome. International Journal of Research in Medical Sciences, 2017. 5(8):

p. 3688-3696.

12. Pqdziwiatr, M., et al., Mechanical bowel obstruction-changes in aetiology over the past 145 years: a single centre retrospective cohort study. Acta Chirurgica Belgica, 2015. 115(6): p. 397-403.

13. Sharma, R., et al., A Clinical Study of Mechanical Small Intestinal Obstruction In Adults.

14. Ten Broek, R.P., et al., Bologna guidelines for diagnosis and management of adhesive small bowel obstruction (ASBO): 2017 update of the evidence-based guidelines from the world society of emergency surgery ASBO working group. World Journal of Emergency Surgery, 2018. 13(1): p. 24.

15. Kumari, P. and R. Ranjan, A Study on Acute Intestinal ObstructionEtiology, Clinical features and Management.

16. Yohannes, M., M. Fanta, and T. Molla, Proportion of intestinal obstruction and associated factors among patients with non traumatic acute abdomen admitted to surgical ward in Debre Birhan referral hospital, north East Ethiopia. American Journal of Biomedical and Life Sciences, 2017. 5(3): p. 54-62.

17. Derseh, T., et al., Clinical Outcome and Predictors of Intestinal Obstruction Surgery in Ethiopia: A Cross-Sectional Study. BioMed Research International, 2020. 2020.

18. Muleta, M.B., Patterns of Surgical Admission at comprehensive specialized and teaching hospital; Addis Ababa, Ethiopia. Ethiopian Medical Journal, 2019. 57(1).

19. Ojo, E., et al., Aetiology, clinical pattern and outcome of adult intestinal obstruction in JOS, north central Nigeria. African journal of medicine and medical sciences, 2014. 43(Suppl 1): p. 29.

20. Drożdż, W. and P. Budzyński, Change in mechanical bowel obstruction demographic and etiological patterns during the past century: observations from one health care institution. Archives of Surgery, 2012. 147(2): p. 175-180.

21. Gadhavi, J.M. and R. Charpot, Clinical study and surgical management of acute intestinal obstruction in the adults. International Surgery Journal, 2020. 7(11): p. 3703-3706.

22. Smeltzer, S., et al., Brunner and Suddarth's Textbook of Medical Surgical Nursing 14th ed. Volume 1, chapter 26, assessment of function. 2014, Lippincott Williams and Wilkins, p685.

23. Ooko, P.B., et al., Pattern of adult intestinal obstruction at Tenwek hospital, in south-western Kenya. Pan African Medical Journal, 2015. 20(1).

24. Bankole, A.O., A.O. Osinowo, and A.A. Adesanya, Predictive factors of management outcome in adult patients with mechanical intestinal obstruction. Nigerian Postgraduate Medical Journal, 2017. 24(4): p. 217.

25. Soressa, U., et al., Prevalence, causes and management outcome of intestinal obstruction in Adama Hospital, Ethiopia. BMC Surg, 2016. 16(1): p. 38.

26. Derseh, T., et al., Management Outcome and Associated Factors among Intestinal Obstruction Patients Treated Surgically, Eastern Ethiopia. 2019.

27. Gebrie, T., T. Handiso, and S. Hagisso, Management Outcome and Associated Factors of Surgically Treated Non Traumatic Acute Abdomen at Attat Hospital, Zone, Ethiopia. Int J Surg Res Pract, 2019. 6: p. 099.

28. Tesfaye, S., D. Teare, and G. Muleta, Prevalence and management outcome of non-traumatic emergrncy surgical acute abdomen at mettu karl referral hospital, iluababur zone, Ethiopia. 2017.

29. Cappell, M.S. and M. Batke, Mechanical obstruction of the small bowel and colon. Med Clin North Am, 2008. 92(3): p. 575-97, viii.

30. Taylor, M.R. and N. Lalani, Adult small bowel obstruction. Acad Emerg Med, 2013. 20(6): p. 528-44. 
31. Soressa, U., et al., Prevalence, causes and management outcome of intestinal obstruction in Adama Hospital, Ethiopia. BMC surgery, 2016. 16(1): p. 38.

32. Kotiso, B. and Z. Abdurahman, Pattern of Acute Abdomen in Adult Patients in Tikur Anbessa Teaching Hospital, Addis Ababa, Ethiopia. East and central African journal of surgery, 2007. 12(1): p. 47-52.

33. Legesse, H., G. Muleta, and S. Ali, Pattern of intestinal obstruction among adult operated patients in jimma university specialized hospital, a two years retrospective review, jimma, south west, Ethiopia. 2012.

34. Wondafrash, B. and M. Abera, Pattern and management outcome of intestinal obstruction among operatively managed adults in Attat Catholic Hospital, Gurage Zone, Southern nations and nationalities regional state, Ethiopia. 2014.

35. Getachew, N., S. Alemu, and T. Kebeta, Associated factors and management outcome of surgically treated adult intestinal obstruction at nekemte referral hospital, oromia, western Ethiopia. 2018.

36. Getahun, B., M. Tesfaye, and G. Muleta, Prevalence, causes and management out come of small intestinal obstruction in nekemte referral hospital, oromia, western Ethiopia. 2017.

37. Karakaş, D.Ö., et al., Etiology, management, and survival of acute mechanical bowel obstruction: Five-year results of a training and research hospital in Turkey. Turkish Journal of Trauma and Emergency Surgery, 2019. 25(3): p. 268280.

38. Kirubagaran, B., K.P.P. Abhilash, and S.L. Sharma, A prospective study to determine the clinical profile of patients suspected to have acute intestinal obstruction in the emergency department. Current Medical Issues, 2019. 17(3): p. 49.

39. Udhayasuriyan, R., Validation of AGESS-SBO scoring system for the prognosis and outcome of small bowel obstruction. 2018, Madras Medical College, Chennai.

40. Deshmukh, S.N. and A.N. Maske, Pattern of dynamic intestinal obstruction in adults at tertiary care centre. International Surgery Journal, 2016. 3(2): p. 492-496.

41. Moghadam, A.G.B. and S.A.S. Harooni, Pattern of dynamic intestinal obstruction in adults. IAIM, 2017. 4(10): p. 230-235.

42. Wismayer, R., Factors Influencing Outcome of Sigmoid Volvulus in Northern Uganda. A Prospective Observational Study. East and Central African Journal of Surgery, 2016. 21(3): p. 85-97.

43. Chalya, P.L. and J.B. Mabula, Sigmoid volvulus and ileo-sigmoid knotting: a five-year experience at a tertiary care hospital in Tanzania. World Journal of Emergency Surgery, 2015. 10(1): p. 1-8.

44. Biondo, S., et al., Large bowel obstruction: predictive factors for postoperative mortality. Diseases of the colon \& rectum, 2004. 47(11): p. 1889-1897.

45. Campbell, F.C., et al., Pattern of Adult Mechanical Intestinal Obstruction in Delta State University Teaching Hospital. studies. 13: p. 15.

46. Purcell, L.N., et al., District general hospital surgical capacity and mortality trends in patients with acute abdomen in Malawi. World journal of surgery, 2020: p. 1-8.

47. Mariam, T.G., A.T. Abate, and M.A. Getnet, Surgical management outcome of intestinal obstruction and its associated factors at University of Gondar Comprehensive Specialized Hospital, Northwest Ethiopia, 2018. Surgery research and practice, 2019. 2019.

48. Dandena, F., et al., Magnitude and Pattern of Inpatient Surgical Mortality in a Tertiary Hospital in Addis Ababa, Ethiopia. Ethiopian Journal of Health Sciences, 2020. 30(3).

49. Shukla, S., et al., Clinico-pathological study of intestinal obstruction and its management. International Surgery Journal, 2017. 4(2): p. 604-611. 
50. Karakaş, D.Ö., et al., Etiology, management, and survival of acute mechanical bowel obstruction: Five-year results of a training and research hospital in Turkey. Ulus Travma Acil Cerrahi Derg, 2019. 25(3): p. 268-280.

51. Chalya, P.L., et al., Dynamic bowel obstruction: aetiology, clinical presentation, management and outcome at Bugando Medical Centre, Mwanza, Tanzania. Tanzania journal of health research, 2014. 16(1).

52. Awedew, A.F., et al., Small bowel volvulus (SBV) in Northcentral Ethiopia. BMC surgery, 2020. 20(1): p. 1-6.

53. Eleweke, N., Prognostic factors of mechanical intestinal obstruction in Aba, Abia State, Nigeria. Journal of Medical Investigation and Practice, 2012. 8: p. 18-21.

54. Tasnim, T., et al., Current spectrum of intestinal obstruction in a teaching hospital. TAJ: Journal of Teachers Association, 2019. 32(1): p. 62-69.

55. Halis, N., et al., Factors Associated with Morbidity and Mortality in Patients with Mechanical Bowel Obstruction. Journal of Academic Emergency Medicine/Akademik Acil Tip Olgu Sunumlari Dergisi, 2012. 11(1).

56. Atalay, M., et al., Magnitude, pattern and management outcome of intestinal obstruction among non-traumatic acute abdomen surgical admissions in Arba Minch General Hospital, Southern Ethiopia. BMC surgery, 2021. 21(1): p. 1-8.

57. Coe, T.M., D.C. Chang, and J.K. Sicklick, Small bowel volvulus in the adult populace of the United States: results from a population-based study. The American Journal of Surgery, 2015. 210(2): p. 201-210. e2.

58. Chalya, P.L., et al., Dynamic bowel obstruction: aetiology, clinical presentation, management and outcome at Bugando Medical Centre, Mwanza, Tanzania. Tanzan J Health Res, 2014. 16(1): p. 38-46.

59. Soressa, U., et al., Prevalence, causes and management outcome of intestinal obstruction in Adama Hospital, Ethiopia. BMC surgery, 2016. 16(1): p. 1-8.

60. Tadelle, G., D. Teare, and T. Teweld, Magnitude and Management Outcome of Sigmoid Volvulus in Tercha General Hospital, SNNPR, South Western Ethiopia. 2017.

61. Aemro, A., A. Jember, and D.Z. Anlay, Incidence and predictors of tuberculosis occurrence among adults on antiretroviral therapy at Debre Markos referral hospital, Northwest Ethiopia: retrospective follow-up study. BMC Infectious Diseases, 2020. 20(1): p. 1-11.

62. Arefayne, I., D. Teare, and D. Bedada, Magnitude, causes and management outcome of small bowel obstruction at metu karl referral hospital, oromia region, south western Ethiopia. 2017.

63. Apanga, S., et al., Post-operative surgical site infection in a surgical ward of a tertiary care hospital in Northern Ghana. Int J Res Health Sci, 2014. 2(1): p. 207-12.

64. Lo, O.S.H., et al., Early outcomes of surgery for small bowel obstruction: analysis of risk factors. Langenbeck's archives of surgery, 2007. 392(2): p. 173-178.

65. Gayathri, V., P. Mali, and H. Harindranath, A clinical study of surgical management of acute intestinal obstruction. International Surgery Journal, 2018. 5(10): p. 3342-3345.

66. Marfil-Garza, B.A., et al., Risk factors associated with prolonged hospital length-of-stay: 18-year retrospective study of hospitalizations in a tertiary healthcare center in Mexico. PloS one, 2018. 13(11): p. e0207203.

67. Reddy, K., et al., Postoperative stay following colorectal surgery: a study of factors associated with prolonged hospital stay. Annals of the Royal College of Surgeons of England, 2003. 85(2): p. 111.

68. Fevang, B.T., et al., Complications and death after surgical treatment of small bowel obstruction: a 35-year institutional experience. Annals of surgery, 2000. 231(4): p. 529.

69. Oldani, A., et al., Emergency surgery for bowel obstruction in extremely aged patients. Minerva chirurgica, 2018. 75(1): p. 11-14.

\section{Figures}

Page 14/16 


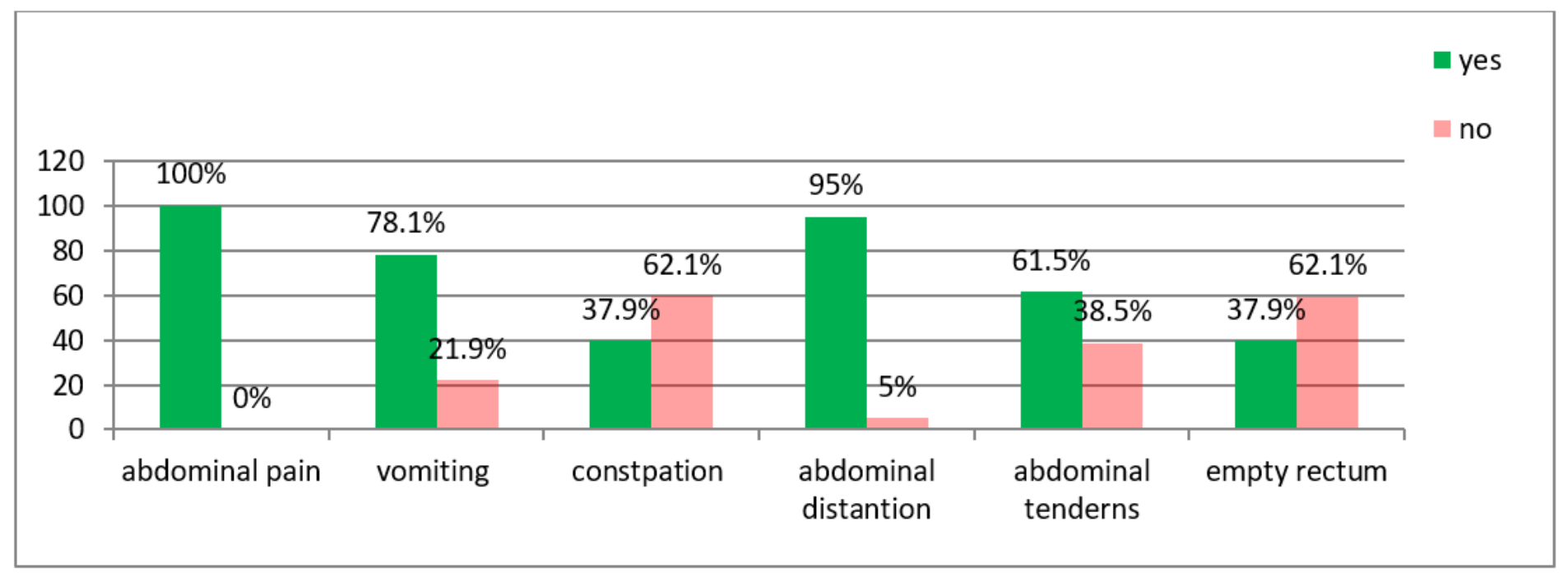

Figure 1

Sign and symptoms of bowel obstruction among patients admitted in surgical ward at Debre Markos Comprehensive specialized hospital North west Ethiopia 2021(n=517)

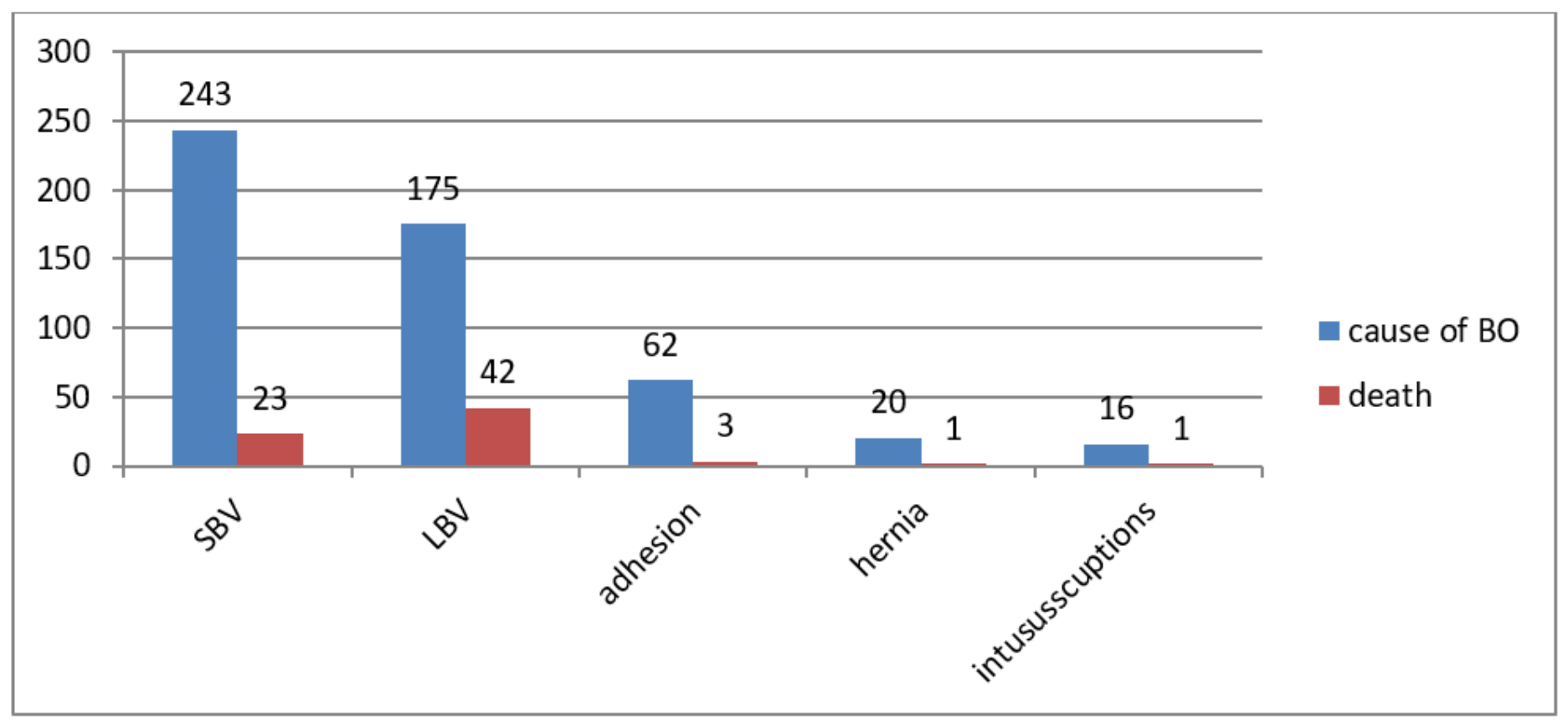

Figure 2

causes and death of bowel obstruction among patients admitted in surgical ward at DMCSH North West Ethiopia $2021(n=517)$ 


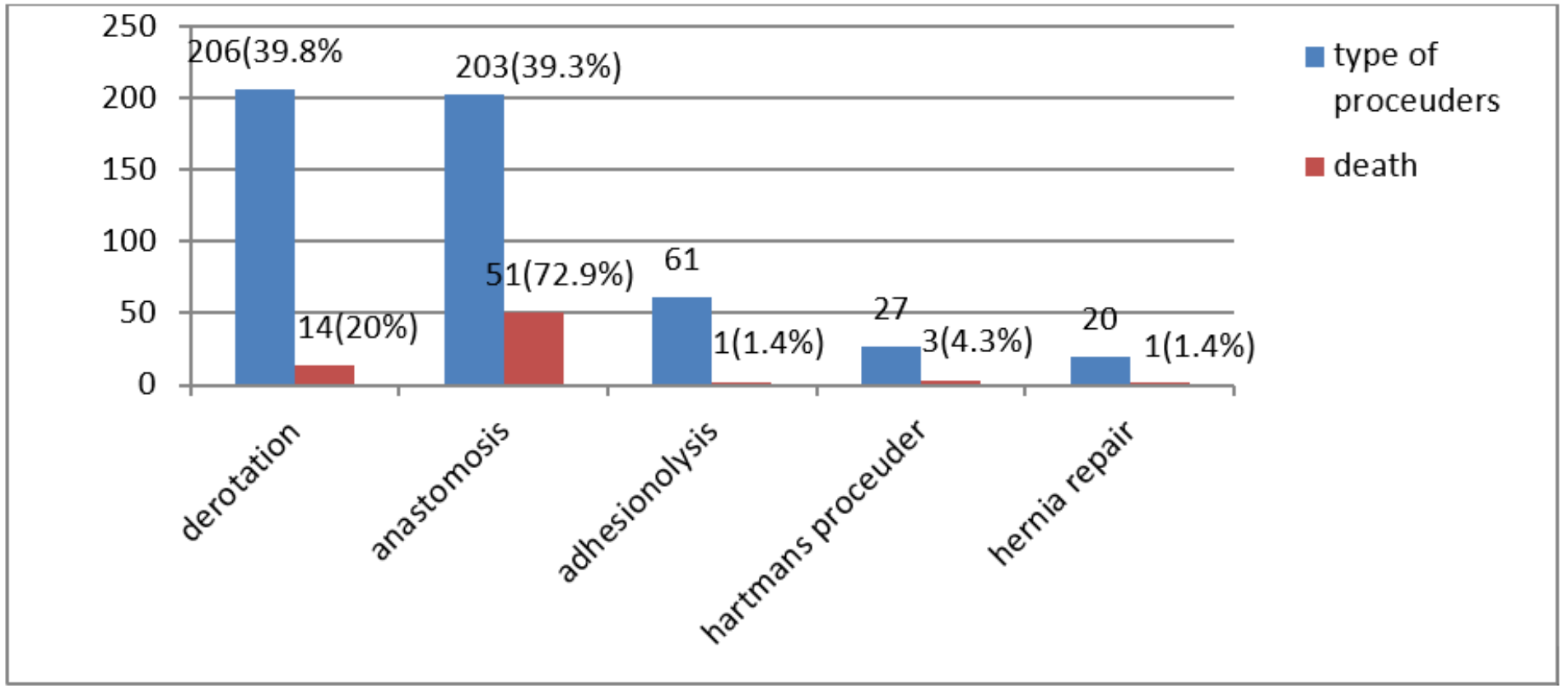

Figure 3

Types of procedure performed and death of patients with bowel obstruction among patients treated surgically at DMCSH North West Ethiopia 2021 $(n=517)$ 